\title{
Comparative Testing of Antibacterial Activity of Aqueous Extract of Bergenia Ligulata Rhizomes and Ethanolic Extract of Butea Monosperma Flowers for Herbal Gel Formulation
}

\author{
Purva Malik $^{1 *}$, Vidhi Bhatia ${ }^{2}$ \\ ${ }^{1,2}$ Department of Pharmacognosy, V. E. S. College of Pharmacy, Chembur, Mumbai 400074, India.
}

\begin{abstract}
The aim of this research was to formulate a gel comprising of the both extracts of Bergenia ligulata rhizomes and Butea monosperma flowers that would aid in wound healing by exhibiting antibacterial activity at the site of wound infection if any. As per the literature survey conducted it was found that aqueous extract of Bergenia ligulata rhizomes and ethanolic extract of Butea monosperma flowers have good potential of antibacterial activity. Hence this antibacterial activity was studied with the help of agar well-diffusion assay method, against the micro-organisms-S. aureus, MRSA, Pr. vulgaris, and E.coli . Both these extracts were obtained through Soxhlet extraction process and this process was optimized to get maximum yield of extraction. By agar gel well- diffusion assay at the concentration of about $100 \mu \mathrm{g} / \mathrm{mL}$ both the extracts exhibited maximum zone of inhibition. This concentration was helpful in deciding the dose for topical gel formulation.
\end{abstract}

Keywords: antibacterial activity, Soxhlet extraction, agar gel well-diffusion assay, Bergenia ligulata,,Butea monosperma

\section{Introduction}

India has a rich heritage of medicinal herbs. With the advent of new technology and innovations in pharmaceutical arena, these medicinal herbs can now be formulated into different herbal formulations. Herbal medicines are still mainly used by $70-80 \%$ of the world's total population, mostly in the developing countries.[5] According to the World Health Organization (WHO), the use of herbal remedies throughout the world exceeds that of the conventional drugs by two or three times. There are about 10,000 plant species which are being used in Indian System of Medicines (ISM) traditional medicines in Indian subcontinent and out of these 450-500 species are mostly used in over $85 \%$ of Ayurvedic, Unani and Siddha formulation and about 40 species are used in modern drugs.[6] Drugs were shortlisted and selected by carrying out review of literature of Research articles and other official books like The Ayurvedic Pharmacopoeia of India. Butea monosperma flower, belonging to family Fabacae, is explored to possess wound healing, anti-oxidant, anti-bacterial and antiinflammatory activities.[9]The flower contains mainly flavonoids butrin $1.5 \%$, isobutrin coreopsin, isocoreopsin and butein.[7]Bergenia ligulata rhizome, belonging to family Saxifragaceae is explored to exhibit anti-bacterial activity. The Phytoconstituents present in Bergenia ligulata rhizomes are gallic acid and tannic acid.[5] These polyphenolic compounds are mainly responsible for antibacterial activity that prevent bacterial infections like sepsis and others arising during wound healing. Bergenin $0.9 \%$ is also a major phytoconstituent acting as a strong antibacterial agent. [4]Agar well diffusion method is widely used to evaluate the antimicrobial activity of plants or microbial extracts or a drug.[5]

\section{Plant Materials and Preparation of Extracts:}

\section{Material And Methods}

The rhizomes of Bergenia ligulata and flowers of Butea monosperma, were purchased from local Kalbadevi market supplier Manilal and Lallubhai sons. and co. in Aug. 2016 and authenticated from Agharkar Research Institute, Pune, India. The rhizomes and flowers were cut into small pieces and dried at controlled temperature $45^{\circ} \mathrm{C}$ and powdered. The powder was then extracted with ethanol [2] under soxhlation to give ethanolic extract of flowers of Butea monosperma and similarly with water [8,1]under soxhlation to give aqueous extract of rhizomes of Bergenia ligulata. These extracts were filtered and evaporated to dryness with a dryer.

\section{Preliminary Phytochemical Screening:}

The ethanolic extract of Butea monosperma flower and aqueous extract of Bergenia ligulata rhizomes; were subjected to a preliminary phytochemical screening for the detection of various plantconstituents i.e. phytoconstituents.

Chemicals:

Muller and Hinton (MH) Agar butts, ethanol A.R grade, distilled water. 
Procedure for Antibacterial Agar well-diffusion Assay:

$20 \mathrm{~mL}$ of sterile, molten \& cooled to $45^{\circ} \mathrm{C}$ Muller Hinton (MH) agar butts were added to sterile big petri dishes containing $0.625 \mathrm{~mL}$ of the $18-24 \mathrm{hr}$ old test pathogens with O.D 1 and the plates were rotated clockwise and anticlockwise so as to distribute the culture uniformly in the medium. The plates were kept undistributed for 10 to 15 mins in order to set the medium properly. Then using a sterile cork-boarer with internal diameter $6 \mathrm{~mm}$ and external diameter $8 \mathrm{~mm}$; four wells were punched in the medium one in each quarter of the plates. $80 \mu \mathrm{L}$ of theantibiotics, herb extract control soframycin etc were then added to each of the well and the plates were kept in the refrigerator for $1 / 2 \mathrm{hr}$ for prediffusion of the sample. Then the plates were incubated at $37^{\circ} \mathrm{C}$ for $24 \mathrm{hr}$., after which the zones of inhibition were read by the zone reader supplied by the Hi-media.

\section{Extraction}

The yield of ethanolic extract of Butea monosperma flowers and aqueous extract of Bergenia ligulata rhizomes obtained were $6.76 \%$ w/w and $4.84 \%$ w/w respectively. The ethanolic extract of Butea monosperma flowers showed presence of phytochemicals namely alkaloids, flavonoids, glycosides, tannins, phenolic compounds and aqueous extract of Bergenia ligulata rhizomes showed the presence of phytochemicals namely flavonoids, glycosides, tannins, phenolic compounds.

The Bergenia ligulata andButea monosperma extracts, Soframycin cream (std) and the gel were dissolved in DMSO where as Penicillin $(5 \mathrm{U} / \mathrm{ml})$ conc. was prepared in Buffer pH6.8 and streptomycin $(100 \mathrm{mcg} / \mathrm{ml})$ conc. in buffer $\mathrm{pH} 7.0$.

\section{Results And Discussion}

As shown in the table 1.0 DMSO shows negligible zone of inhibition, ethanolic extract of Butea monosperma flower exhibited better antibacterial activity in comparison with soframycin cream. Aqueous extract of Bergenia ligulata rhizomes also showed antibacterial activity except against MRSA .The formulated gel was also found to have very good antimicrobial activity, except for MRSA where it was comparatively less. The antibiotics definitely have a better role to play in treatment of infections.

The results of zone of zones of inhibition of the drug / chemical /antibiotic used are as shown in the table 1.0

Table no. 1 Results showing zone of inhibition of test microorganisms against both the extracts and formulated gel

\begin{tabular}{|c|c|c|c|c|c|c|c|c|}
\hline \multirow{2}{*}{$\begin{array}{l}\text { Test } \\
\text { organisms } \\
\text { used }\end{array}$} & \multicolumn{8}{|c|}{$\begin{array}{l}\text { Drug / chemical /antibiotic used } \\
\text { (Diameter of zone of inhibition in } \mathbf{m m} \text { ) }\end{array}$} \\
\hline & DMSO & $\begin{array}{l}\text { Bergeni } \\
l \text { extract }\end{array}$ & $\begin{array}{l}\text { Soframycin } \\
\text { cream }\end{array}$ & $\begin{array}{l}\text { Butea } \\
\text { extract }\end{array}$ & $m$ & Gel & Penicillin & Streptomycin \\
\hline S. aureus & $\begin{array}{l}1.33 \\
0.000\end{array}$ & $\begin{array}{l}24.67 \\
1.247\end{array}$ & $14.33 \pm 0.471$ & $\begin{array}{l}21.67 \\
1.247\end{array}$ & \pm & $\begin{array}{ll}30.33 & \pm \\
1.247 & \end{array}$ & $\begin{array}{l}38.33 \\
1.247\end{array}$ & $20.67 \pm 1.247$ \\
\hline MRSA & $\begin{array}{l}1.33 \\
0.471 \\
\end{array}$ & $\begin{array}{l}16.00 \\
0.816\end{array}$ & $13.33 \pm 0.471$ & $\begin{array}{l}0.67 \\
0.471 \\
\end{array}$ & \pm & $\begin{array}{ll}11.67 & \pm \\
0.943 & \end{array}$ & $\begin{array}{l}23.67 \\
1.247\end{array}$ & $22.33 \pm 0.471$ \\
\hline Pr. vulgaris & $\begin{array}{l}1.33 \\
0.471\end{array}$ & $\begin{array}{l}21.00 \\
1.700\end{array}$ & $14.00 \pm 0.816$ & $\begin{array}{l}11.67 \\
0.471\end{array}$ & & $\begin{array}{ll}25.67 & \pm \\
1.700 & \end{array}$ & $\begin{array}{l}39.67 \\
2.055\end{array}$ & $17.00 \pm 1.633$ \\
\hline E. coli & $\begin{array}{ll}1.00 \\
0.000\end{array}$ & $\begin{array}{l}16.33 \\
1.247\end{array}$ & $13.67 \pm 0.471$ & $\begin{array}{l}14.00 \\
1.633\end{array}$ & & $\begin{array}{ll}15.00 \quad \pm \\
0.816\end{array}$ & $\begin{array}{ll}29.00 & \pm \\
0.816 & \end{array}$ & $17.67 \pm 0.471$ \\
\hline
\end{tabular}

Key:S. aureus= Staphylococcus aureus MRSA= Methicillin resistant Staphylococcus aureus Pr. vulgaris= Proteus vulgarisE. coli= Escherichia coli

The results of antibacterial activity of penicillin, DMSO, soframycin and streptomycin and that of Butea. $m$ extract, Bergenia. $l$ extract, and gel against MRSA, S aureus, Proteus vulgarisand E.coli are shown in figures from 1.1to1.8

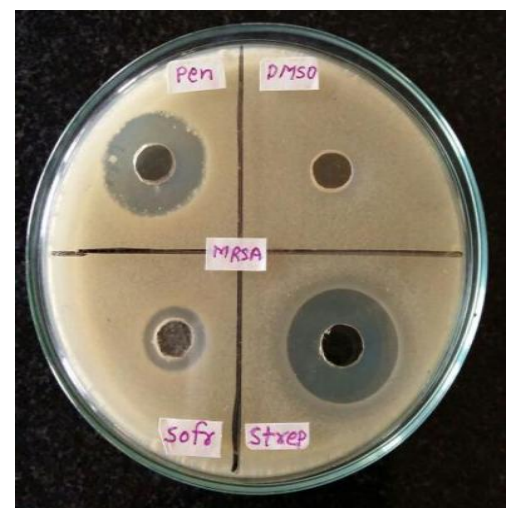

Fig No. 1.1: Antibacterial activity of penicillin, DMSO, Soframycin and streptomycin againstMRSA 


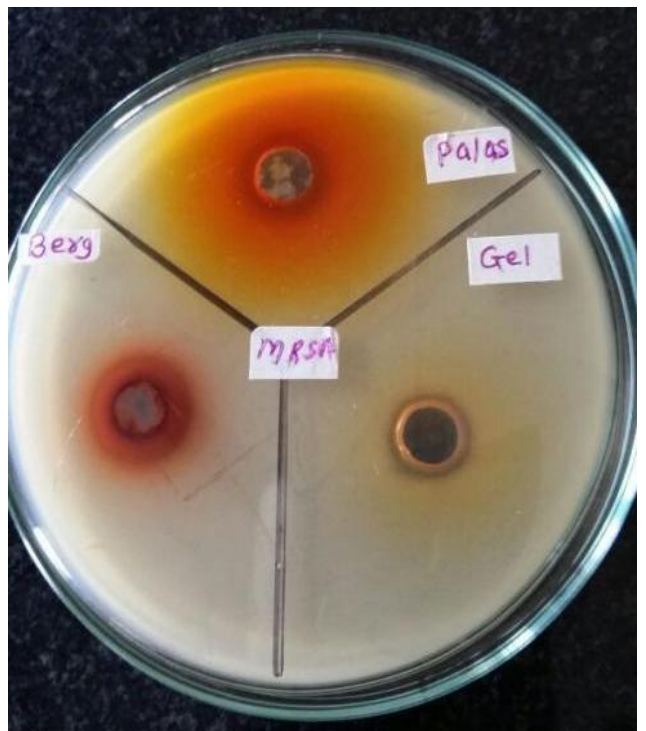

Fig No. 1.2: Antibacterial activity of Butea. $m$ extract, Bergenia. $l$ extract, and gel against MRSA

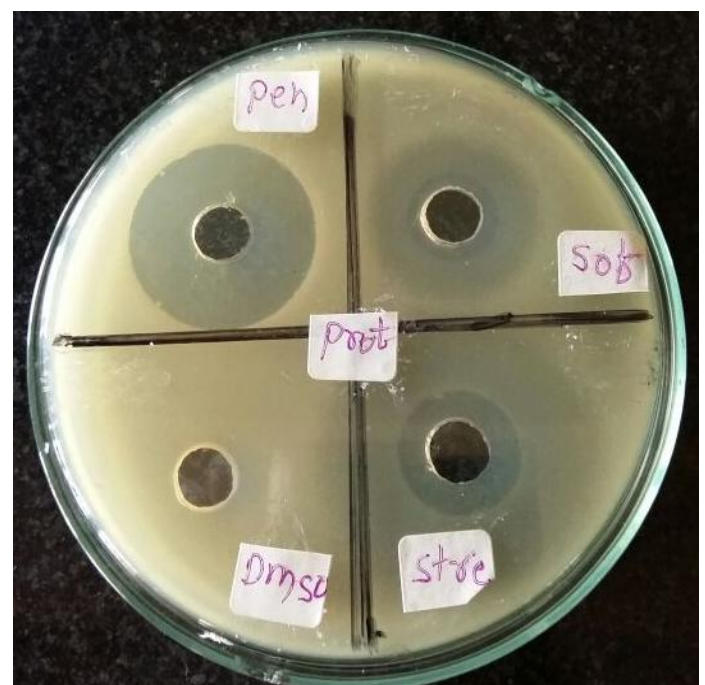

Fig No. 1.3: Antibacterial activity of penicillin, DMSO, Soframycin and streptomycin againstP.vulgaris

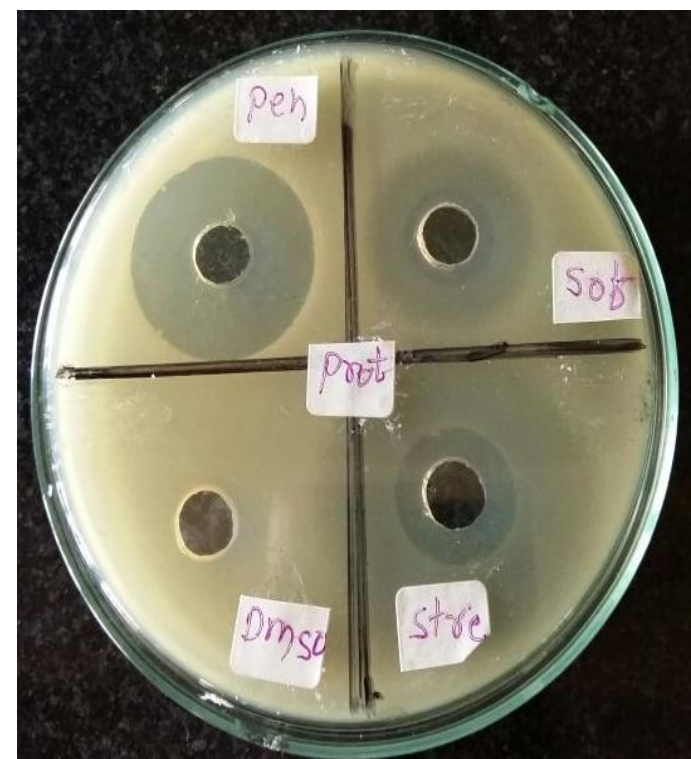

Fig No. 1.4: Antibacterial activity of Butea. $m$ and Bergenia. $l$ extract, and gel against $P$. vulgaris 


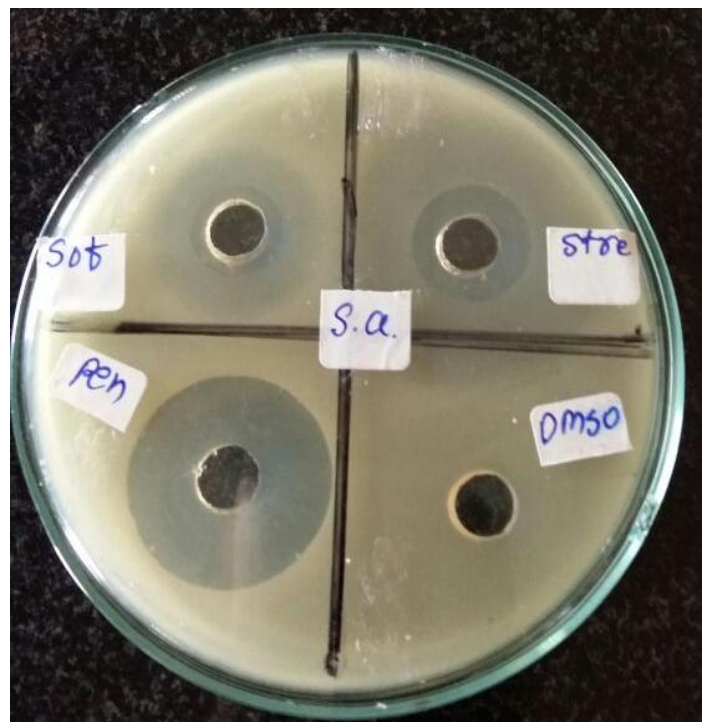

Fig No. 1.5: Antibacterial activity of penicillin, DMSO, Soframycin and streptomycin against S. aureus

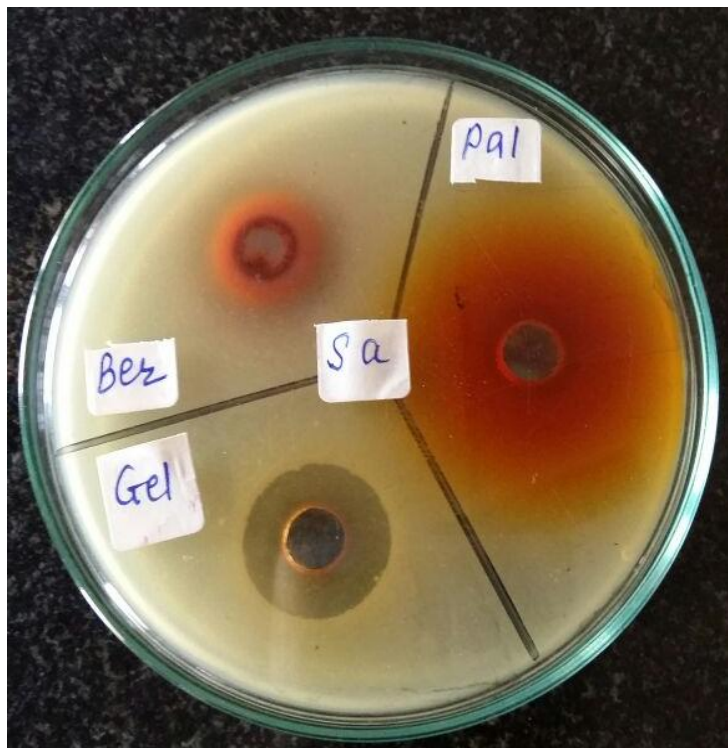

Fig No.1.6: Antibacterial activity of Butea. $m$ and Bergenia. $l$ extract, and gel against $\mathrm{S}$. aureus

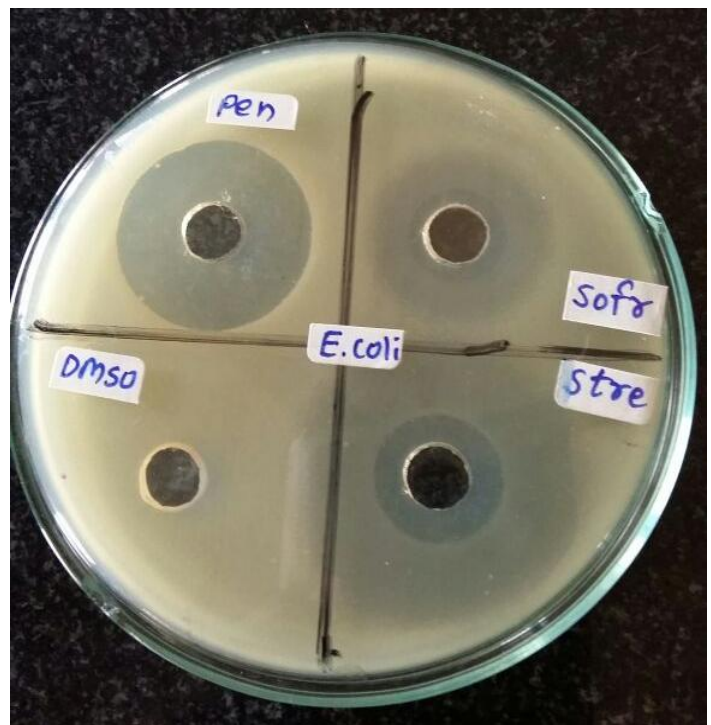

Fig No. 1.7: Antibacterial activity of penicillin, DMSO, Soframycin and streptomycin against E. coli 


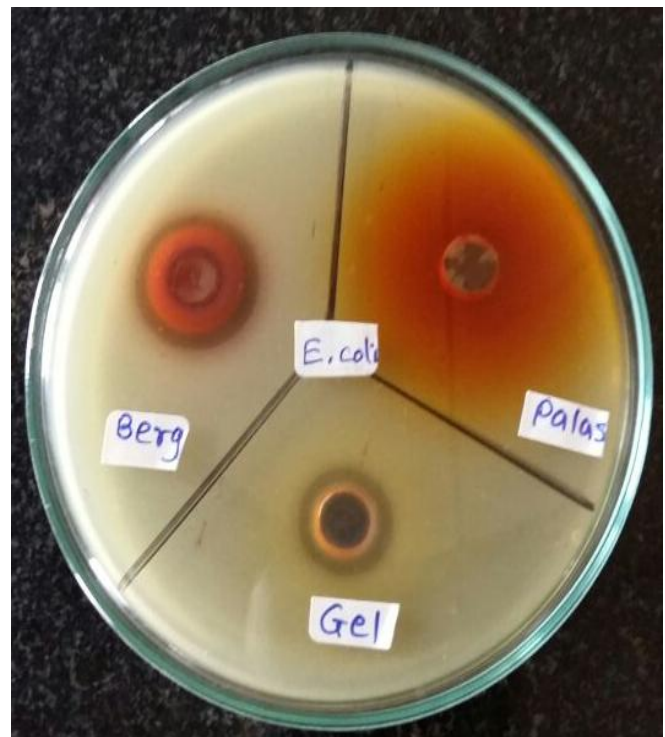

Fig No. 1.8: Antibacterial activity of Butea. $m$ extract, Bergenia. $l$ extract, and gel against $E$. coli

Dunnets' statistical method with help of GRAPHPAD PRISIM SOFTWARE VERSION 6.6; was applied to test whether the data obtained and results were statistically significant or not. The results of the same are as follows:The Dunnets' test applied exhibited the result that the results obtained were statistically significant.[10]Results of Dunnets' statistical test for antibacterial assay are as shown in fig 1.9 below.

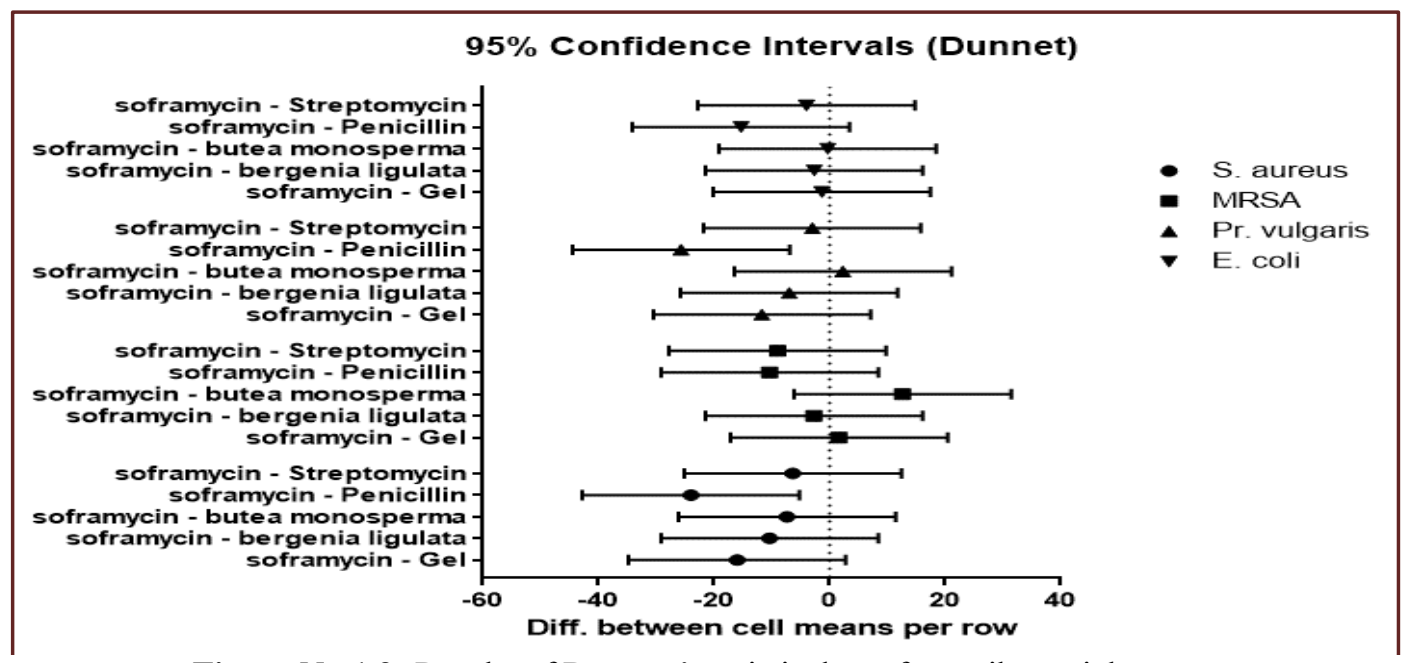

Figure No.1.9: Results of Dunnets' statistical test for antibacterial assay

\section{Conclusion}

The above studies have demonstrated that both the ethanol \& aqueous extract of Butea monosperma flowers and Bergenia ligulata rhizomes respectively have antibacterial properties. Although as expected aqueous extract of Bergenia ligulata rhizomes has more antibacterial activity. Further studies to elucidate the exact antibacterial mechanism of Bergenia ligulata rhizomes especially and Butea monosperma flowers need to be explored. In-vivo studies also need to be done to correlate with the in-vitro results.

We would like to thank-

\section{Acknowledgement}

1. Agharkar Pune Institute for providing us the authentication of our crude drugs of both rhizomes and flowers.

2. P. D. Hinduja Hospital for providing us the micro-organisms for antibacterial assay.

3. Principal, V. E. S. College of Pharmacy, Chembur, Mumbai 400074 for providing use with the necessary infrastructure. 


\section{References}

[1]. AnVdriCahyoKumoroet al, Effects of solvent properties on the Soxhlet extraction of diterpenoid lactones from Androraphispaniculata leaves, Science Asia 35 (2009); 306-309.

[2]. Aye AyeTunet al, Isolation and characterization of Flavonoids from the Flowers of Butea monosperma Lam (Pauk), The Jour. Myan. Acad. Arts and Sci. 2004, 2(1):2; 86-90.

[3]. CleidsonValgaset al, Screening methods to determine antibacterial activity of natural products, Braz. J. Microbiol. vol.38 no.2 Sao Paulo Apr./June 2007

[4]. Gurav and Gurav, A comprehensive review: Bergenia ligulatawall-a controversial clinical candidate, IJPSR (2014), Vol (5): 16301642 .

[5]. Kataria Sahil et al, Standardisation of medicinal plant materials, IJRAP, 2 (4), 1100-1109, 2011

[6]. Khajuria K. Ravi. Agarwal S.G. "Principles of Quality Control, Standardization and Chemo profiling of Medicinal Plants and ISM Preparation" Nov 2006

[7]. Mishra S.H., Lavhale, Evaluation of free radical scavenging activity of Butea monosperma Lam. Indian Journal of Experimental Biology Vol (45), April 2007. Pg 376-384

[8]. VanitaG.Kanaseet al, Evalauation of in-vitro immunomodulatory activity of Aqueous and ethanolic extract of Capparismooni, International Journal of Pharma and Bio Sciences, 2013; 4(2): 344-352.

[9]. Yeoh S. The influence of iron and free radicals on chronic leg ulceration. Prim Intention 2000; 8: 47-55.

[10]. Jaki T- 2013Dunnetts'Statistical evaluation of toxicological assaysNov;87(11):1901-10 